\title{
The consequences for memory of imagining in another person's voice
}

\author{
MARCIA K. JOHNSON \\ Princeton University, Princeton, New Jersey \\ MARY ANN FOLEY \\ Skidmore College, Saratoga Springs, New York \\ and \\ KEVIN LEACH \\ State University of New York at Stony Brook, Stony Brook, New York
}

\begin{abstract}
Subjects listened to and imagined words and then attempted to discriminate words they had heard from words they had imagined. Discrimination was better when subjects imagined themselves saying the words (Experiments 1 and 2) than when subjects imagined the words in the speaker's voice. Subjects also had more difficulty discriminating imagined from perceived words when they imagined in the speaker's voice than when they imagined words in a voice other than their own or the speaker's (Experiment 1). The results are consistent with the idea that reality monitoring is affected by the degree of similarity in sensory characteristics of memories derived from perception and from imagination (Johnson \& Raye, 1981).
\end{abstract}

Johnson and Raye (1981) used the term reality monitoring to refer to the processes involved in discriminating memories of perceptions from self-generated memories produced by thoughts and fantasies. According to the Johnson-Raye model, reality monitoring involves evaluating characteristics of memories, such as sensory and contextual information, semantic detail, and information about cognitive operations. Reality monitoring is possible because memories based on self-generated processes and memories based on perceptual processes typically differ with respect to these characteristics. For example, self-generated memories tend to have less sensory information than do perceptual memories.

The average difference in the underlying sensory characteristics of memories from external and those from internal sources provides one basis for reality monitoring decisions. A substantial amount of sensory information included in a memory suggests that the memory was external in origin, and very little sensory information suggests that the memory was internal in origin. Because these are only "average" differences, sometimes attribution errors are made. It follows that the greater the similarity in the amount of sensory information in these two types of memories, the poorer reality monitoring will be.

\footnotetext{
Preparation of this article was supported in part by National Institute of Mental Health Grant MH 37222, and in part by National Science Foundation Grant BNS-8510633. We would like to thank Carol Raye, Evan Chua-Yap, and Hugh Foley for their helpful comments on earlier drafts of this paper. Kevin Leach is currently at the Department of Psychology, Harvard University. Requests for reprints should be sent to Marcia K. Johnson, Department of Psychology, Princeton University, Princeton, NJ 08544.
}

Furthermore, insofar as perception and imagination tend to be qualitatively different within any particular characteristic, this, too, could be a basis for reality monitoring, even if memories of perceived and imagined events were not different in quantitative ways. For example, if a child's brother spoke in a low voice and their imaginary playmate "spoke" in a high-pitched voice, then voice quality provides a potential cue about the origin of a remembered statement. Thus it also follows that the more specific qualitative similarity (e.g., in voice quality, physical appearance of the speakers, environmental features, semantic content) there is between memories from external and internal sources, the more likely they will be confused (Johnson \& Raye, 1981).

The results of an experiment by Johnson, Raye, Wang, and Taylor (1979) provide some support for the importance of sensory information in reality monitoring. Johnson et al. asked subjects to estimate the frequency with which they had seen pictures of familiar objects. The more often subjects had generated images of the pictures, the higher their frequency estimates. More to the present point, good imagers were less able than poor imagers to separate memories for the pictures from their memories of the imagined pictures. Johnson et al. attributed the greater confusion to the presumably greater overlap in sensory information of perceived and imagined memories in good imagers than in poor imagers.

The present experiments were also directed at the issue of whether "surface characteristics" of imagination affect the degree to which imagination is confused with perception. Rather than rely on a subject variable such as imagery ability, as in Johnson et al.'s (1979) study, we introduced an instructional variable to manipulate the 
similarity of perception and imagination. Subjects were instructed either to imagine words in their own voices or to imagine words in the voice of another person. Later, in both conditions, subjects attempted to discriminate words they imagined from words they heard the other person say. Our primary interest was the effect of this manipulation on reality monitoring decisions. To the extent that subjects are successful in thinking in the other person's voice, we expected the overlap between perceived and imagined sensory information to be greater in the condition in which the subject thinks in the other person's voice. This similarity should reduce the usefulness of sensory information as a cue to the origin of a memory, and thus reality monitoring should be poorer when subjects think in the other person's voice than when they think in their own voices.

A reduction in reality monitoring when subjects think in the other person's voice compared with when they think in their own voices may involve two factors. Imagining in one's own voice might tend to be more abstract (involve less sensory information) than imagining in another person's voice; thus reality monitoring would be easier in the former case because of quantitative differences in sensory information between memories for perceived and memories for imagined events. Alternatively, thinking in one's own voice might produce as much sensory information in memory as thinking in another person's voice, but the specific qualitative similarity of memories of perceived and imagined items should be greater in the case of thinking in the other person's voice. An additional condition included in Experiment 1 helped us isolate the effects of the second factor, qualitative similarity. In this condition, subjects listened to one person say words and imagined a different person say other words. Later, subjects attempted to discriminate imagined from heard words. The amount of sensory information generated during imagining should be equivalent in the two conditions in which subjects imagine in voices other than their own. However, reality monitoring should be poorer when subjects think in the speaker's voice than when they think in some other person's voice. This is because the specific qualitative similarity of the memories of imagined items to heard items should be greater when subjects think in the speaker's voice than when they think in some other person's voice.

\section{EXPERIMENT 1}

\section{Method}

Subjects. The subjects were 24 male and female undergraduate volunteers from the State University of New York at Stony Brook; they were randomly assigned to the three conditions.

Materials and Procedure. In the Listen(a)-Imagine(s) condition, subjects $(n=8)$ listened to a female lab assistant (person A) say some words and thought of themselves (S) saying other words. For example, the experimenter might have said, "Kathy, say bird," and Kathy (A) repeated the word "bird." For other items, the ex- perimenter cued the subject to imagine himself/herself saying a word, for example, "John, imagine saying the word tree," and John imagined himself pronouncing the word "tree." In the Listen(a)-Imagine(a) condition, subjects ( $n=7)$ listened to person A say some words and imagined hearing person A say other words. For example, the experimenter might have said, "Kathy, say bird," and Kathy repeated the word "bird." For other items, the experimenter cued the subject to imagine person A saying a word, for example, "John, imagine Kathy saying the word tree," and the subject thought of Kathy pronouncing the word "tree." To help the subjects imagine the voice of an unfamiliar person, person A read a short paragraph aloud before the experiment began, and the subjects were asked to pay special attention to the characteristics of A's voice. In the Listen(a)-Imagine(b) condition, a second assistant (person B) read the sample paragraph, and the subjects $(n=9)$ imagined in this person's voice. Thus, subjects in this condition heard words spoken by person $A$ and imagined words spoken by person $B$. The particular assistants serving as A and B were counterbalanced and randomly assigned across subjects. In addition, the assistants randomly served as $\mathrm{A}$ in the Listen(a)-Imagine(a) condition.

Sixty words that represent familiar objects (e.g., tree, bird, fire, moon) were used; a random half were used as new words in a later memory test. The other 30 words were randomly assigned to the two types of items within each condition (the assignment of items was reversed randomly across subjects). The order of items was random, with the restriction that both types of items occurred equally often in each quarter of the sequence.

After the acquisition phase, the experimenter chatted with the subject for about $3 \mathrm{~min}$, then gave a surprise memory test. Old and new items were randomly intermixed and presented orally by the experimenter one at a time at a 5-sec rate. In the Listen(a)-Imagine(s) condition, the subjects decided whether each test item was one they had heard A say, one they had imagined saying, or a new word. In the Listen(a)-Imagine(b) condition, the subjects decided whether each test item was one they had heard A say, or they had imagined B say, or a new word. In the Listen(a)-Imagine(a) condition, the subjects decided whether each test item was one they had actually heard A say, one they had imagined A say, or a new word.

At the beginning of the experiment, the subjects were given a general cover story that we were studying various aspects of perception and imagination, but they were not warned that there would be a subsequent memory test. All subjects appeared to understand the instructions, and no subjects reported that they were unable to imagine in another person's voice.

\section{Results and Discussion}

The mean proportions of "imagine," "listen," and "new" responses to each type of item in each condition are shown in Table 1.

Old-new recognition. Performance in each condition was first scored without regard for whether subjects identified the source of items correctly. The measure of oldnew recognition was (number of hits + number of correct rejections)/number of test items (i.e., 60 ). In this measure, a "hit" is either a "listen" or an "imagine" response to an old item, and a correct rejection is a "new" response to a new item. As can be seen in Table 2, the overall level of correct old-new recognition was about $80 \%$, and the three groups did not differ significantly $[F(2,21)=1.57, M S \mathrm{e}=.01, p>.05]$. The fact that the three conditions had generally comparable old-new 
Table 1

Mean Proportion of Responses to Each Type of Item in Experiment 1

\begin{tabular}{|c|c|c|c|c|c|c|c|c|c|}
\hline \multirow[b]{3}{*}{ Response } & \multicolumn{9}{|c|}{ Condition } \\
\hline & \multicolumn{3}{|c|}{ Listen(a)-Imagine(s) } & \multicolumn{3}{|c|}{ Listen(a)-Imagine(b) } & \multicolumn{3}{|c|}{ Listen(a)-Imagine(a) } \\
\hline & $L(a)$ & $\mathrm{I}(\mathrm{s})$ & New & L(a) & I(b) & New & L(a) & I(a) & New \\
\hline Imagine & .07 & .79 & .02 & .12 & .56 & .06 & .12 & .34 & .06 \\
\hline Listen & .72 & .12 & .15 & .55 & .17 & 10 & .60 & .44 & .09 \\
\hline New & .21 & .09 & .84 & .33 & .27 & .83 & .28 & .22 & .85 \\
\hline
\end{tabular}

Note-L $=$ Listen; $\mathrm{I}=$ Imagine; $\mathbf{a}=$ Person $\mathbf{A} ; \mathbf{b}=$ Person $\mathbf{B} ; \mathrm{s}=$ Self.

Table 2

Recognition and Identification of Origin Scores in Experiment 1

\begin{tabular}{lccc}
\hline & Listen(a)-Imagine(s) & Listen(a)-Imagine(b) & Listen(a)-Imagine(a) \\
\hline Recognition & & & \\
(Hits + Correct Rejections) & .84 & .77 & .80 \\
Identification of Origin & .89 & .78 & .62 \\
\hline
\end{tabular}

Note--a $=$ Person $\mathrm{A} ; \mathrm{b}=$ Person $\mathrm{b} ; \mathrm{S}=$ Self.

recognition is convenient because the interpretation of potential differences among conditions in differentiating between listen and imagine items need not be qualified by considering differences in ability to discriminate old from new items. Also, insofar as recognition and identification of origin respond differently to particular variables, the difference supports the idea that the two types of tasks draw on somewhat different information in memory (Johnson \& Raye, 1981).

Identification of origin. A discrimination score, which reflects the ability to distinguish imagined from heard items, was computed for each subject: This score is analogous to the identification-of-origin scores used in other reality monitoring studies (e.g., Finke, Johnson, \& Shyi, 1988; Johnson, Raye, Foley, \& Foley, 1981; Raye \& Johnson, 1980). In the present context, it was defined as the proportion of items identified as old that were also correctly identified as imagine (I) or listen (L) items:

$$
[\mathbf{I}|\mathbf{I}+\mathbf{L}| \mathbf{L}] /[\mathbf{I}|\mathbf{I}+\mathbf{L}| \mathbf{I}+\mathbf{L}|\mathbf{L}+\mathbf{I}| \mathbf{L}] \text {. }
$$

The mean scores for each condition are shown in Table 2.

The three groups differed in their abilities to discriminate heard and imagined items $[F(2,21)=10.75$, $M S \mathrm{e}=.01, p<.001]$. Subsequent planned comparisons indicated that the Listen(a)-Imagine(b) group had marginally lower scores than the Listen(a)-Imagine(s) group $[F(1,15)=3.66, M S e=.01, p<.075]$, and, more important, the Listen(a)-Imagine(a) group had significantly lower scores than either the Listen(a)-Imagine(s) group $[F(1,13)=36.31, M S e=.01, p<.001]$ or the Listen(a)-Imagine(b) group $[F(1,14)=6.18, M S e=$ $.016, p<.05]$. Thus, as expected, the subjects had most difficulty discriminating imagined from heard items when they imagined in the speaker's voice.

There are two possible types of confusion errors in this situation: (1) a subject can mistakenly call an item he/she heard the other person say an imagined item, and (2) a subject can mistakenly call an item he/she imagined a listen item (see Table 1). There are two interesting aspects of these data. First, the tendency to misidentify an item that the subject heard another person say as one the subject imagined (a listen item called an imagine item) was relatively rare and fairly comparable across the three conditions $[F(2,21)<1]$. Second, the tendency to misidentify an imagine item as a listen item differed among the conditions $[F(2,21)=9.45, M S \mathrm{e}=5.21, p<.001]$ and was greatest in the Imagine(a)-Listen(a) condition. Thus, in the present situation, making imaginations similar to perceptions reduced subjects' abilities to discriminate imagined from heard items by selectively increasing the probability that an imagined event would be misclassified as a perception. In addition, the absolute magnitude of the confusion was quite large; subjects who imagined in the speaker's voice identified about half of the imagined items they recognized as old as listen items (.44 vs. .34 in Table 1).

\section{EXPERIMENT 2}

In natural contexts, confusions between what others said and what we imagined they might say occur not only after we communicate face-to-face, but also after we talk on the telephone or exchange letters. In fact, under such conditions of "impoverished" perceptual input, confusions might be particularly likely. The primary purpose of Experiment 2 was to provide a replication of the major finding of Experiment 1 and, at the same time, to extend the conditions to a situation in which the speaker was not physically present. In Experiment 2, the voice that presented the Listen(a) words occurred only on audiotape; the assistant was not present in the room with the subject. An additional change from Experiment 1 to Experiment 2 was from a between-subject to a within-subject comparison of Listen(a)-Imagine(s) and Listen(a)Imagine(a) discriminations. In the acquisition phase of Experiment 2 , subjects were presented with an equal number of words to listen to an assistant say [Listen(a)], words to imagine in their own voice [Imagine(s)], and words to 
imagine in the voice of the assistant [Imagine(a)]. The discrimination phase required distinguishing between words that were previously heard and those that were imagined the subjects were not required to identify in whose voice they imagined words. Two scores were then compared, one reflecting the subject's ability to discriminate Imagine(s) items from Listen(a) items and one reflecting the subject's ability to discriminate Imagine(a) items from Listen(a) items.

\section{Method}

Subjects. Fifteen women participated in the experiment as a favor to one of the authors (K.L.).

Materials. Thirty-six concrete nouns were selected from West's (1953) A General Service List of English Words (each item had a frequency count of from 14 to 228). Four sets of nine items each were constructed by random assignment of words to set. The four word sets were then randomly crossed with the four conditions [Listen(a), Imagine(s), Imagine(a), and New] and counterbalanced so that each word occurred in each condition. The conditions were presented in blocked fashion to the subjects. The three acquisition conditions [Listen(a), Imagine(s), and Imagine(a)] could have been presented in six possible orders, each of which could have been represented by four different assignments of word sets to conditions. Fifteen of the 24 possible combinations were randomly selected. The order of presentation of each condition [Listen(a), Imagine(s), and Imagine(a)] was counterbalanced across subjects.

Within each of the resulting combinations of word lists, five words from each set were randomly selected to be presented first; the same process was repeated for the remaining four words for each set. For example, if the order of word presentation in the acquisition phase was Imagine(s)-Imagine(a)-Listen(a), the subject was presented with five Imagine(s) words, followed by five Imagine(a) words, followed by five Listen(a) words, followed in order by four each of Imagine(s), Imagine(a), and Listen(a) words.

A male experimenter $(E)$ and a female assistant made 15 separate tape-recorded presentations of word lists prior to the collection of data. The interstimulus interval between word presentations was approximately $5 \mathrm{sec}$. The word presentations took the following forms: For Listen(a) words, E said “Carol, say --.-." This was followed by the assistant saying that word. For Imagine(s) words, E said "Imagine saying ----,"' and for Imagine(a) words, E said "Imagine Carol saying ----." A short practice tape was also made, and another tape was made of the assistant (A) reading a passage from a fairy tale to provide subjects with prior exposure to the voice in which they would be asked to imagine words.

Finally, five separate recognition memory lists were constructed, consisting of all 36 words spoken by $E$. The order of the words in the lists was determined randomly, with the restriction that no more than 2 consecutive words from any one condition [Listen(a), Imagine(s), Imagine(a), and New] could occur. Recognition memory lists were counterbalanced across the 15 word presentation lists, such that no recognition list was associated with any given assignment of words to conditions or with order of conditions more than once.

Procedure. The subjects were tested individually by the experimenter. Each subject was seated in a room and read the following:

Now we are going to do a task that involves imagining. Part of this task involves imagining words in the voice of another person. In order to acquaint you with this voice, I am going to play a short tape of a woman reading a passage from a children's fairy tale. The woman reading the passage is named Carol. Please pay attention to how her voice sounds, because shortly you will be asked to imagine words in her voice.
A 90 -sec passage of the assistant reading was then played, followed by the experimenter continuing, as follows:

Now that you have heard Carol's voice, I will explain how this imagining task will proceed. I am going to play another tape. On this tape you will hear my voice giving instructions. Some of the time you will hear me tell Carol to say the word of a common object like "television" or "pencil." This will be followed by Carol saying that word. Your task is simply to listen to Carol say the word. Some of the time you will hear my voice on the tape give the instruction to imagine saying the word of a common object such as "coat." Your task is to imagine saying that word-that is, you think the word to yourself but do not say it out loud. Finally, some of the time you will hear me give the instruction to imagine Carol saying the word of a common object like "briefcase." Your task is to imagine the word in Carol's voice. That is why I played the tape of Carol reading-so you will know what Carol's voice sounds like. You will be given $5 \mathrm{sec}$ in which to do each task, and it will always be clear by the instruction on the tape whether you are to listen to Carol say a word, or imagine a word in your own voice, or imagine a word in Carol's voice. First, let's do a practice test.

A practice tape was then played, and the subjects were questioned about whether or not they could perform the tasks. Approximately half of the tape of the assistant reading from the fairy tale was then replayed to assure that the subjects were well-acquainted with the voice. The stimulus tape was then played on the tape recorder, and followed with a short passage from a fairy tale that the subjects read aloud. This last step was taken to prevent rehearsal. The subjects were then informed for the first time of the memory test. The experimenter read each item from the list, and the subjects were instructed to state one of three responses: "Carol said it," "I imagined it," or "Not presented" (for words that were new). It was made clear that even words that were imagined in Carol's voice were considered imagined words. The subjects were told to guess at words about which they were not certain. The experimenter recorded each response and waited for the subject to respond before reading the next item.

As in Experiment 1, all subjects appeared to understand the instructions, and no subjects reported that they were unable to imagine in another person's voice.

\section{Results and Discussion}

The subjects' responses to each type of item, expressed as proportions, are shown in Table 3.

Old-new recognition. As is clear from Table 3, the number of hits (old items called imagine or listen) was about $75 \%$ and did not vary with condition $(F<1)$, indicating equal levels of old-new recognition for Listen(a), Imagine(s), and Imagine(a) items.

Identification of origin. Identification-of-origin scores, comparable to those computed for Experiment 1, were calculated for each subject according to the following for-

Table 3

Proportion of Total Responses to Each Type of Item in Experiment 2

\begin{tabular}{lccccc}
\hline & \multicolumn{4}{c}{ Type of Item } \\
\cline { 2 - 3 } Response & Listen(a) & & Imagine(s) & Imagine(a) & New \\
\hline Imagine & .19 & & .58 & .41 & .10 \\
Listen & .55 & & .18 & .35 & .07 \\
New & .26 & .24 & .24 & .83 \\
\hline
\end{tabular}

Note $-\mathrm{a}=$ Person $\mathrm{A} ; \mathrm{s}=$ Self. 
mulas: The ability to discriminate between Imagine(a) and Listen(a) words is given by

$$
[\mathrm{I}|\mathrm{I}(\mathrm{a})+\mathrm{L}| \mathrm{L}(\mathrm{a})] /[\mathrm{I}|\mathrm{I}(\mathrm{a})+\mathrm{L}| \mathrm{I}(\mathrm{a})+\mathrm{L}|\mathrm{L}(\mathrm{a})+\mathrm{I}| \mathrm{L}(\mathrm{a})] \text {. }
$$

The ability to discriminate between Imagine(s) and Listen(a) words is given by

$$
[\mathrm{I}|\mathrm{I}(\mathrm{s})+\mathrm{L}| \mathrm{L}(\mathrm{a})] /[\mathrm{I}|\mathrm{I}(\mathrm{s})+\mathrm{L}| \mathrm{I}(\mathrm{s})+\mathrm{L}|\mathrm{L}(\mathrm{a})+\mathrm{I}| \mathrm{L}(\mathrm{a})] \text {. }
$$

Analysis of these discrimination scores indicates that discriminating between Imagine(a) and Listen(a) words $(M=.64)$ was significantly worse than discriminating between Imagine(s) and Listen(a) words $(M=.75)[F(1,14)$ $=7.21, M \mathrm{Se}=.02, p<.02]$. Thus, as in Experiment 1, it was more difficult to discriminate an imagined word from a perceived word when the imagination and perception were in the same "voice" than when they were in different voices.

The three types of confusion errors possible in this situation are shown in Table 3. These errors are mistakenly calling an Imagine(s) or Imagine(a) word a listen word, or calling a Listen(a) word an imagined word. Planned comparisons showed that confusion errors occurred significantly more often for Imagine(a) items than for Imagine(s) items $[F(1,14)=6.87, M S \mathrm{e}=2.35, p<.02]$, and that the number of confusion errors for Imagine(s) and Listen(a) words were nearly identical $[F(1,14)<1]$. As in Experiment 1, the absolute amount of confusion was large; subjects misattributed $35 \%$ of the items imagined in the speaker's voice to the speaker, compared with $41 \%$ correct attributions to the speaker (next to last column in Table 3). Thus again about half of the items imagined in the speaker's voice that were recognized as old were misattributed to the speaker.

Despite several changes in procedure (a tape-recorded voice rather than a physically present assistant, the use of a repeated measures design rather than independent groups, and approximately half of the total number of items), the major finding of Experiment 1 was replicated: identification of the origin (internal vs. external) of verbal information was more difficult when subjects imagined words in the same voice in which other words were presented auditorially. That is, making imaginations more similar to perceptions decreased subjects' ability to identify the source of the imaginations as internal. As in Experiment 1 , analysis of confusion errors supported the conclusion that this decrement in memory performance was due primarily to the tendency to misattribute words imagined in the assistant's voice to the assistant, a phenomenon that occurred less often when subjects imagined words in their own voices.

\section{GENERAL DISCUSSION}

There is considerable evidence that people tend to remember schematized representations or the "gist" of events (see Alba \& Hasher, 1983, for a review). However, a number of investigators have suggested that memory preserves relatively specific records of original events (e.g., Alba \& Hasher, 1983; Jacoby \& Brooks, 1984; Johnson, 1983; Johnson \& Raye, 1981; Kolers \& Ostry, 1974; Kolers \& Roediger, 1984) that may persist along with internally generated mental representations (Johnson \& Raye, 1981). Part of the information that specifies an event is its "surface characteristics"-where it happened, the color or sounds involved, and so forth. A number of findings indicate that people do retain information about surface characteristics of events they have perceived (e.g. . Craik \& Kirsner, 1974; Jacoby \& Dallas, 1981; Kolers, 1975; Light \& Berger, 1976) or imagined (Geiselman \& Glenny, 1977; Johnson, Raye, Foley, \& Kim, 1982; Johnson et al., 1979).

Although the memory system may be highly veridical in the sense that it preserves records of its past perceptual and self-generated processing, we still make errors in memory. One of the most important potential mechanisms of error and distortion is a failure to discriminate the origin of memories. This presumably comes about because decisions about the origin of events are made using imperfect decision processes or decision processes applied to incompletely retrieved information. The model of reality monitoring proposed by Johnson and Raye (1981) is an attempt to specify some of the factors that should be important in decisions about the origin of memories. Johnson and Raye focused on discriminating between external and internal sources of memories, but such "source monitoring" judgments are quite general (Johnson, 1988; Lindsay \& Johnson, 1987). That is, the basic issues and logic of reality monitoring apply to discriminating between memories from any two sources, for example, visual and verbal sources (e.g., Loftus, Miller, \& Burns, 1978) or two speakers (e.g., Foley, Johnson, \& Raye, 1983; Harvey, 1985; Raye \& Johnson, 1980), or between two types of memories from the same source, for example, ideas and actions (R. Anderson, 1984; Foley et al., 1983; Foley \& Johnson, 1985).

The present result-namely that it is particularly hard to discriminate what you imagined from what someone else said if you imagined in the speaker's voice-fits within this general framework. Difficulty in discriminating the origin of memories depends on the quantitative and qualitative similarity in information from two sources, in this case, information specifying the surface characteristics or sensory aspects of the perceived and imagined events. The fact that the disruption was greater when subjects imagined in the speaker's voice than when subjects imagined in some other person's voice clearly demonstrates that qualitative similarity in characteristics of perceived and imagined memories creates a problem of discriminating between them. Furthermore, sensory similarity can produce quite dramatic levels of confusion, as indicated by the fact that, across experiments, items imagined in the speaker's voice that were identified as old were erroneously attributed to the speaker about half the time.

Finally, the fact that memory for surface characteristics affects reality monitoring argues against a "tagging" 
notion, whereby memories are simply tagged as externally derived or internally generated (e.g., J. R. Anderson, 1983; Flavell, Flavell, \& Green, 1983). According to a tagging notion, errors in reality monitoring would occur because the external/internal tag for a memory is lost or not retrieved in an all-or-none fashion. Simple external/internal tagging would produce equal discrimination of origin, no matter what the "voice" of the imagined events. That is, the tagging notion does not easily account for variations in difficulty of reality monitoring as a function of qualitative characteristics of the imagination. The present results are more consistent with the idea that reality monitoring decisions are based on evaluating activated characteristics, including sensory information, of previously experienced events. The more the characteristics of memories for imagination and perception overlap, the harder the discrimination will be.

\section{REFERENCES}

Alba, J. W., \& Hasher, L. (1983). Is memory schematic? Psychological Bulletin, 93, 203-231.

ANDERSON, J. R. (1983). A spreading activation theory of memory. Journal of Verbal Learning \& Verbal Behavior, 22, 262-295.

ANDERSON, R. (1984). Did I do it or did I imagine doing it? Journal of Experimental Psychology: General, 113, 549-615.

Craik, F. I. M., \& Kirsner, K. (1974). The effect of a speaker's voice on word recognition. Quarterly Joumal of Experimental Psychology, 26, 274-284.

Finke, R. A., Johnson, M. K., \& Shyi, G. C.-W. (1988). Memory confusions for real and imagined completions of symmetrical visual patterns. Memory \& Cognition, 16, 133-137.

Flavell, J. H., Flavell, E. R., \& Green, F. L. (1983). Development of the appearance-reality distinction. Cognitive Psychology, 15, 95-120.

Foley, M. A., \& Johnson, M. K. (1985). Confusions between memories for performed and imagined actions: A developmental comparison. Child Development, 56, 1145-1155.

Foley, M. A., Johnson, M. K., \& Raye, C. L. (1983). Age related changes in confusion between memories for thoughts and memories for speech. Child Development, 54, 51-60.

Geiselman, R. E., \& GlenNy, J. (1977). Effects of imagining speakers' voices on the retention of words presented visually. Memory \& Cognition, 5, 499-504.

HaRVEY, P. D. (1985). Reality monitoring in mania and schizophrenia. The Journal of Nervous \& Mental Disease, 173, 67-73.

JACOBY, L. L., \& BroOKs, L. R. (1984). Nonanalytic cognition:
Memory, perception, and concept learning. In G. H. Bower (Ed.), The psychology of learning and motivation (Vol. 18, pp. 1-47). New York: Academic Press.

JACOBY, L. L., \& DALLAS, M. (1981). On the relationship between autobiographical memory and perceptual learning. Joumal of Experimental Psychology: General, 110, 306-340.

Johnson, M. K. (1983). A multiple entry, modular memory system. In $\mathrm{G}$. H. Bower (Ed.), The psychology of learning and motivation (Vol. 17, pp. 81-123). New York: Academic Press.

JoHnson, M. K. (1988). Discriminating the origin of information. In T. R. Oltmanns \& B. A. Maher (Eds.), Delusional beliefs: Theoretical and empirical perspectives. New York: Wiley.

Johnson, M. K., \& RA YE, C. L. (1981). Reality monitoring. Psychological Review, 88, 67-85.

Johnson, M. K., Raye, C. L., Foley, H. J., \& Foley, M. A. (1981). Cognitive operations and decison bias in reality monitoring. American Journal of Psychology, 94, 37-64.

Johnson, M. K., RAye, C. L., Foley, M. A., \& KiM, J. K. (1982). Pictures and images: Spatial and temporal information compared. Bulletin of the Psychonomic Society, 19, 23-26.

Johnson, M. K., Raye, C. L., WANG, A. Y., \& TAYLoR, T. H. (1979). Fact and fantasy: The roles of accuracy and variability in confusing imaginations with perceptual experiences. Journal of Experimental Psychology: Human Learning \& Memory, 5, 229-240.

Kolers, P. A. (1975). Specificity of operations in sentence recognition. Cognitive Psychology, 7, 289-306.

Kolers, P. A., \& Ostry, D. J. (1974). Time course of loss of information regarding pattem analyzing operations. Journal of Verbal Learning \& Verbal Behavior, 13, 599-612.

Kolers, P. A., \& Roediger, H. L., III. (1984). Procedures of mind. Journal of Verbal Learning \& Verbal Behavior, 23, 425-449.

Light, L. L., \& Berger, D. E. (1976). Are there long-term "litera] copies" of visually presented words? Journal of Experimental Psychology: Human Learning \& Memory, 2, 654-662.

LindSAY, D. S., \& Johnson, M. K. (1987). Reality monitoring and suggestibility: Children's ability to discriminate among memories from different sources. In S. J. Ceci, M. P. Toglia, \& D. F. Ross (Eds.), Children's eyewitness memory (pp. 92-121). New York: SpringerVerlag.

LofTus, E. F., Miller, D. G., \& Burns, H. J. (1978). Semantic integraton of verbal information into a visual memory. Journal of $E x$ perimental Psychology: Human Learning \& Memory, 4, 19-31.

RAYE, C. L., \& JohnSON, M. K. (1980). Reality monitoring vs. discriminating between external sources of memories. Bulletin of the Psychonomic Society, 15, 405-408.

WEST, M. P. (1953). A general service list of English words (rev. ed.). New York: Longmans.

(Manuscript received February 2, 1987; revision accepted for publication December 22, 1987.) 